The article discusses aesthetic premises linked to phenomenology. It's presented a model of stratification based on the theory of the polish philosopher Roman Ingarden and its application in works of the technology art. Is also presented an analysis from the application of this method in the work Rara Avis, of Eduardo Kac. Keywords: aesthetics, phenomenology, technological art. 


\section{Fenomenologia da Cibercepção}

Cleomar

ROCHA

O artigo discute premissas estéticas vinculadas à fenomenologia, apresentando um modelo de estratificação da obra de arte tecnológica, baseado no trabalho do filósofo polonês Roman Ingarden. Á apresentada também uma análise a partir da aplicação do método, no trabalho Raras Avis, artista brasileiro Eduardo Kac.

Palavras-chave: estética, fenomenologia, arte tecnológica. 
Desde Edmund Husserl (2001), com sua teoria fenomenológica, vários são os autores que se debruçam sobre esse referencial, na construção e/ou desenvolvimento da atitude fenomenológica, fundada na relação objeto e sujeito, colocando a noção de intencionalidade no centro das discussões filosóficas. O filósofo Mikel Dufrenne esclarece:

A intencionalidade significa, no fundo, a intenção do Ser que se revela - a qual não é outra coisa que sua revelação - e suscita o sujeito e o objeto para se revelar. O objeto e o sujeito, que só existem no seio da mediação que os une, são, destarte, as condições do advento de um sentido, os instrumentos de um Logos" (DUFRENNE, 1998, p. 79).

Husserl (2001) discute a intencionalidade a partir das estruturas da ordem do noético (noesis), o ato de cogitar, e o noema (adjetivo: noemático) ao seu conteúdo, "o que deixa bem clara a relação sujeito-objeto, que é o fundamento da consciência" (RAMOS, 1969, p.59). Heidegger (apud DUFRENNE, 1998), por outro lado, identifica o Logos com o Ser, o objeto com o ente e o sujeito com o Dasein (e não mais como consciência), enfatizando o poder do Dasein de se abrir ao Ser, mas

(...) determinando essa transcendência ao próprio Ser que convida o sujeito para lhe servir de testemunha, para se fazer o lugar de uma presença, de modo que o seu projeto é um projeto do Ser sobre ele. Assim, objeto e sujeito são destituídos de suas prerrogativas; é o Ser como luz que comanda tanto o olhar, quanto a coisa olhada, que tem a iniciativa da relação entre o sujeito e o objeto (apud DUFRENNE, 1998, p. 79).

Ainda neste sentido, ao estabelecer que a análise do cogito revela que o sujeito é projeto do objeto, a análise intencional revela que o aparecer do objeto é sempre solidário com a intenção que visa a esse objeto.

Há, neste sentido, que se mencionar o a priori da experiência estética, que vem a ser o algo de comum entre sujeito e objeto, de modo que "algo do objeto está presente no sujeito antes de toda experiência e que, em troca, algo do sujeito pertence à estrutura do objeto anteriormente a qualquer projeto de sujeito" (DUFRENNE, 1998, p. 87). 
Questões gerais à parte, e embora Edmund Husserl (2001) não tenha escrito uma estética propriamente dita, sua obra possui vários elementos que permitem a elaboração de uma estética fenomenológica. Um de seus primeiros discípulos, - ainda no tempo de Göettingen - o filósofo polonês Roman Ingarden, elaborou, em 1931, uma análise altamente técnica da obra de arte literária, utilizando os métodos da «fenomenologia» de Husserl para atingir distinções como a dos estrados. O método de Ingarden, publicado no livro Das literarische Kunstwerk, é considerado o primeiro texto organicamente articulado, empenhado em responder à exigência de superação do psicologismo que caracterizou a filosofia no final do século XIX1. O método é composto por cinco estratos da obra literária, sendo a primeira o estrato sonoro, a partir do qual surge o segundo estrato: as unidades de sentido. As palavras se organizam para comporem sintagmas e padrões de frase. Dessa estrutura sintática emergirá um terceiro estrato, o dos objetos representados, o mundo do romancista, as personagens, o ambiente. Os dois últimos estratos, o estrato do mundo e o estrato de qualidades metafísicas, argumentam Wellek e Warren (1962), podem ser tidos em um único, o do mundo, no reino dos objetos representados. Para Ingarden, o estrato do mundo é encarado de um particular ângulo de visão, que não carece necessariamente de ser expresso, pois pode ser implícito. Já o estrato de qualidades metafísicas (o sublime, o trágico, o terrível, o sagrado) seria aquele cuja contemplação nos pode ser proporcionada pela arte. Este estrato, ainda em comentário de Wellek e Warren, pode não ser indispensável e estar ausente de algumas obras literárias. Trata-se, em última instância, da mensagem estética, de que fala Abraham Moles.

O pensamento de Roman Ingarden veio para o Brasil a partir dos estudos de René Wellek e Austin Warren, no livro Teoria da Literatura, de edição portuguesa. A professora Maria Luiza Ramos publica, em 1969, Fenomenologia da obra literária, em que estuda e aplica o método de Ingarden, esclarecendo-o em grande parte. De fato o método de Ingarden é bastante interessante, na medida em que se constrói de modo articulado, permitindo enxergar o exercício hermenêutico a partir de estratos 
que se somam, em um contínuo analítico, fundado no princípio sonoro, alcançando o metafísico. Desse modo o princípio do método é a obra viva, tornada som, que articula palavras em frases, que organizam as unidades de sentido, que estruturam os objetos representados, que compõem o mundo que abraça a metafísica. Esse contínuo sustenta uma atitude fenomenológica, cuja base encontra-se em Husserl, que diz claramente de ir à obra mesma, no sentido de que a obra suscita no intérprete a chave interpretativa, hermenêutica, base para compreensão da intencionalidade, e que de outro modo é explicado a partir da evidência, "ou seja, em experiências em que as 'coisas' e os 'fatos' em questão me são apresentados 'em si'" (HUSSERL, 2001, p. 31).

Certamente mantém-se, desse modo, a premissa fenomenológica do primado da percepção, de Maurice Merleau-Ponty (1999). Contudo, no que tange à arte contemporânea, e de modo mais exato a arte tecnológica, é preciso acrescentar a valoração das instâncias conceituais, abstratas, que fogem à orientação de aproximação sensível, por representação, de que fala Merleau-Ponty. De fato, ao estabelecer reconhecimentos puramente conceituais, e não sensíveis, ainda que admitindo-se a primazia da percepção, o conhecimento intelectual afigura-se em uma representação de igual modo conceitual, validandose não por reconhecimento perceptivo, mas por informação em que se deposita confiança, não verificável, ou não dado à verificação. Significa isso dizer que o agente fruidor depende de informações conceituais e perceptivas para aproximar-se da obra tecnológica, podendo ser enganado nas informações, sem maior dificuldade, haja vista não haver possibilidades de conferências imediatas das informações tidas. Determinadas obras ditas não-lineares com navegação randômica poderiam ser, de fato, completamente lineares, na exata medida em que o percurso lineariza a existência, no que uma experiência com uma obra não-linear e uma segunda com outra linear poderiam ser exatamente iguais, no modo da percepção, e diferentes na intencionalidade, no que resultaria experiências fruitivas distintas. Neste ponto, cognição e percepção caminham juntas, na forma elaborada por Ascott (2002), da cibercepção. 
Mas retomando Ingarden, e não obstante seu método ter sido definido em sua obra, há de notar a possibilidade de variações de estratos, como nota Ramos (1969) ao dizer que buscou, com seu livro, fazer enxergar as margens de formulação de novos estratos, conforme a natureza da obra ou o objetivo do crítico. De fato, Ramos faz coro com Wellek e Warren (1962), que defendem a estruturação de novos estratos, segundo a natureza do trabalho. Ela mesma, Ramos, a despeito de Ingarden não ter formulado um estrato óptico, acrescenta-o em sua análise, justificando-o em função da importância que a organização espacial passa a ter na contemporaneidade.

Ao estabelecer que os estratos seguem a natureza da obra ou o objetivo do crítico, torna-se lícito proceder a uma análise de obras outras, que não literárias, mantendo-se as diretrizes do método de Ingarden, a saber, partindo da dimensão sensível da obra, chegando à dimensão metafísica.

Deste modo, e inspirado na construção de uma estratificação para abordar a obra de arte visual, e a vertente tecnológica desta mais precisamente, alterando os estratos a serem verificados, propõe-se:

- Estrato sensível, abordando as relações sonoras, visuais, olfativas, táteis e cinéticas, na abordagem do objeto estético propriamente dito;

- Estrato pragmático, que considera os aspectos técnicos relacionados à intelecção ou reconhecimento de padrões tecnológicos do 'em si' do objeto, bem como a noção de 'para si' tecnologizado, a partir da inteligência artificial e especificidades do meio;

- Estrato sintático-compositivo, que consiste na observação das unidades de sentido, compreendendo estas enquanto as relações estruturais da(s) linguagem(ns) utilizada(s);

- Estrato semântico, buscando dar conta dos objetos representados, no exercício da relação sígnica;

- Estrato da mensagem estética, ou das qualidades metafísicas, vislumbrando a contemplação, participação ou interação proporcionada pela arte. 
Estes cinco estratos, se não garantem um meticuloso estudo da obra de arte, sistematiza sua abordagem, considerando seus elementos primordiais enquanto tal, mantendo uma orientação de contínuo, partindo da relação fenomenológica sujeito e objeto. Ademais, ultrapassa os modelos estéticos apresentados, ao reestabelecer os valores de subjetivação da qual fala a fenomenologia husserliana.

O presente modelo é denominado Fenomenologia da $\mathrm{Ci}$ bercepção, em referência à base fenomenológica da qual deriva, e da instância da aplicação prioritária, a vertente tecnológica da arte, considerada a partir das abordagens perceptivas e cognitivas, ampliadas pela tecnologia, que originam o termo cunhado por Roy Ascott (2002), um pioneiro da arte tecnológica, como já observado. Outrossim, cabe salientar a possibilidade de aplicação do método em trabalhos artísticos de outras linguagens, tradicionais ou experimentais, haja vista sua origem, sua constituição e amplitude, além da flexibilidade de formação dos estratos, de acordo com a natureza da obra e/ ou objetivo do crítico.

Finalmente, o modelo metodológico diz respeito a abordagem de objetos estéticos e sensações estéticas, envolvendo inteiramente o fruidor como condição da significação da obra, sua existência mesma, na relação fenomenológica sujeito e objeto, no desvelamento do Ser pela intencionalidade, na estrutura noético-noemática. Neste sentido, o método, ao reportar à essa relação como totalidade e na totalidade, firmase enquanto estética, no sentido dado por Pareyson (1997), ao tempo em que remonta, também, as relações poéticas baseadas na produção e participação da obra dita aberta - e de catarsis, quando há uma empatia entre o público e a obra. Ainda, e do mesmo modo que em Ingarden, não há homogeneidade entre os diversos estratos, podendo determinados trabalhos terem um estrato mais rico que outros, ou mesmo terem estratos nulos, de modo a permitir que os estratos se compensem e se complementem na tensão dinâmica geradora da coerência interna da estrutura. 


\section{Aplicação do método}

A título de exemplificação da aplicação do método, é apresentada a seguir a análise da obra Rara Avis, produzida em 1996 pelo brasileiro Eduardo Kac.

O trabalho de Eduardo Kac é amplamente discutido, sendo referido por vários textos críticos e teóricos, a exemplo do que fazem Simone Osthoff (professora de Crítica de Arte da Penn State University, EUA), David Hunt (Crítico de Arte, EUA), Gerfried Stocker (Diretor Artístico do Ars Electronica Festival e Diretor Geral do Ars Electronica Center, Áustria), Steve Tomasula (professor da Notre Dame University, Indiana, EUA), Arlindo Machado (professor da Pontifícia Universidade Católica de São Paulo), Cláudia Giannetti (Diretora do Media Center of Arts and Design, MECAD, Espanha), dentre outros.

Giannetti (2002) aborda o trabalho Rara Avis a partir de uma descrição genérica da instalação, situando os mecanismos de interatividade e telepresença. O efeito de ubiqüidade proporcionada pela obra é o interesse da pesquisadora, bem como a possibilidade de compatilhamento das imagens captadas pelos "olhos" da arara-robô, via Internet.

La instalación está permanentemente conectada a Internet y permite que participantes remotos también observen el espacio de la galería desde el punto de vista del telerrobot. Así, el cuerpo del pájaro artificial es compartido, en tiempo real, por participantes locales y participantes a distancia, de cualquier parte del mundo, a través de Internet (GIANNETTI, 2002, p. 93)².

A pesquisadora brasileira ilustra o texto com documentos técnicos sobre a instalação e também com uma fotografia da galeria, a partir dos olhos da ave robô. Não há aqui uma análise do trabalho, mas sim sua utilização enquanto exemplo na construção de seu argumento de tese.

Arlindo Machado (2000), em capítulo destinado a examinar o trabalho de Kac, consegue ser mais sintético ao comentar Rara Avis. Sua abordagem descreve a obra genericamente, buscando indicar a utilização de robôs em trabalhos artísticos. Novamente não se constitui uma análise, mas de situar esta obra enquanto a primeira em que o artista utiliza de tecnologia para 
compartilhar a visão de um pássaro com seres humanos, sendo o pássaro também uma máquina.

(...) esta foi a primeira vez, em sua obra, que humanos puderam compartilhar o corpo de um pássaro que ao mesmo tempo era uma máquina, e viver, ao menos em um sentido psicológico ou metafórico, a experiência de 'serem' tanto pássaro quanto máquina (MACHADO, 2000, p. 81).

Gerfried Stocker (2003) de modo similar comenta o trabalho, em texto do catálogo "Genesis", da mostra do Centro de Arte Contemporâneo O. K., em Linz, na Áustria. Trata-se de uma descrição rápida da instalação, no que ela tem de tecnologia e efeitos. Não há outro interesse se não pontuar o trabalho, como medida de apresentação do artista para uma exposição.

(...) "Rara Avis" (1996), an interactive telepresence installation, in which a telerobotic bird-machine is put together with real birds and artificial plants in an enclosure. Using data glasses or via Internet, visitors are not only able to control the head of the cybernetic bird, but also to assume its perspective, observe themselves with its camera eyes ("Genesis", 2000. Catálogo)3.

Já o artista descreve Rara Avis a partir, principalmente, da relação estabelecida entre o espectador e a obra, em uma descrição do processo interativo possibilitado. Novamente, o interesse em explorar os efeitos produzidos pela tecnologia e possíveis, explicitando seus mecanismos de produção, posiciona-se de modo privilegiado, ainda que não haja uma descrição técnica minuciosa do aparato usado, exposto, contudo, na forma de gráficos técnicos. Diz Kac que a obra

(...) remete o espectador ao espaço interior e exterior do aviário simultaneamente e propõe uma troca de papéis. A partir do momento que o espectador coloca o capacete virtual ele vê o espaço como se fosse o papagaio robótico. Os pássaros reais e o papagaio robótico (que possui duas câmeras nos olhos) estão num viveiro de frente aos visitantes. Com o visor de realidade virtual, os espectadores passam a ver e ouvir como se fossem o papagaio. 0 papagaio também toma o lugar do espectador, cuja visão é apreciada pelos monitores dos computadores remotos. Diretamente 
ligado à Internet, o participante transmite seu ponto de vista à rede, e dela recebe os sons vocais do telerrobô, que afetam o ambiente local. ${ }^{4}$

Há de se considerar o caráter inovador dos trabalhos do artista brasileiro, no que se refere à utilização de tecnologias diversas, no que o estrato pragmático se firma enquanto o elemento melhor explorado em suas obras, ainda que não se perca, em nenhum momento, preocupações plásticas, semânticas e estéticas, não apenas em Rara Avis, como no conjunto da obra do artista brasileiro.

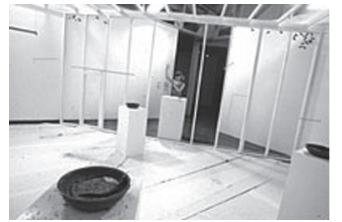

Detalhes da obra Rara Avis

Fonte: Eduardo Kac, <http://www.ekac.org>

Rara Avis é uma instalação que consiste em uma grande gaiola de pássaros com uma arara robô entre eles. A arara robô é dotada de câmeras nos olhos, podendo mover a cabeça para os lados. As imagens captadas pelas câmeras são disponibilizadas em óculos estereoscópicos, disponíveis fora da gaiola, para os visitantes da exposição, com imagens disponíveis pela Internet. Os movimentos da cabeça da ave, e que direcionam sua visada, são controlados pelo visitante, que enxerga pelos olhos da ave, em tempo real. Pela Internet se pode acompanhar as imagens captadas pelo robô, em uma experiência de telepresença ${ }^{5}$. Deste modo o visitante tem a visão interna da gaiola, podendo enxergar a si mesmo fora da gaiola. O som também é captado pela arara, em tempo real. Seu ponto de vista difere de seu ponto de existência, dandoIhe um estar fora de si. O efeito da estereoscopia proporciona uma experiência vívida da imagem, resultando em movimentos voluntários de tentar tocar os outros pássaros. É preciso esclarecer que os visitantes se posicionam de frente a gaiola, enxergando, sem os óculos, os pássaros e a arara robô. A experiência remete à ubiqüidade, possibilidade de estar em dois lugares ao mesmo tempo.

Analisando o estrato sensível, verifica-se que os dados imagéticos são os mais importantes, sendo as informações sonoras 
e as cinestésicas mantidas em segundo plano. Claro está que a movimentação dos óculos, que resultam na movimentação da cabeça da arara e por conseguinte no direcionamento das câmeras, importam, mas o fazem na medida exata em que direcionam a visada, prevalecendo a intenção de ver, antes da intenção de mover o robô.

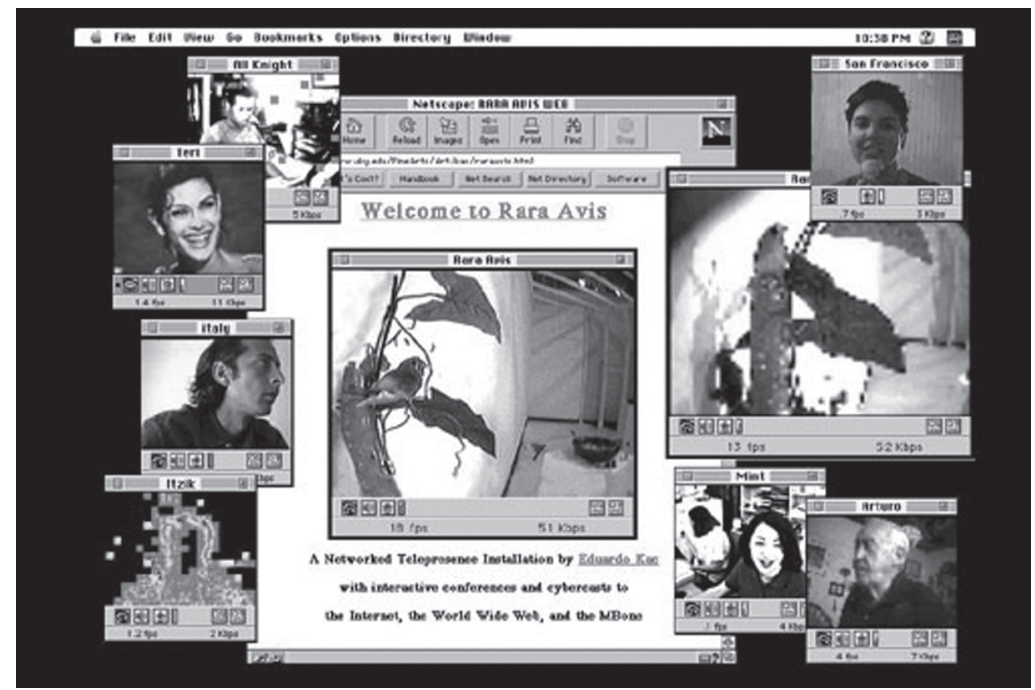

Detalhe da obra Rara Avis

Fonte: Eduardo Kac, <http://www.ekac.org>

A gaiola é ampla e toda branca, inclusive as barras de proteção que sustentam uma tela. Recipientes com água e comida de pássaros podem ser vistos no interior do viveiro. Em um canto, um arbusto artificial sustenta a arara robô, multicor e de tamanho ampliado em relação à escala natural. A arara permanece pousada. Diversos pequenos pássaros reais vivem na gaiola, convivendo com o robô. Um praticável também branco está situado de frente a gaiola, e que serve de anteparo para os óculos estereoscópicos e os fios que se conectam a eles. O visitante deve se posicionar ali para usar os óculos, tendo a sua frente, do lado oposto da gaiola, o robô, que visualmente prende o olhar, pela coloração e tamanho. A arara tem predominância da cor vermelha, com detalhes em azul e amarelo. Sua fronte é branca, com olhos pretos e bico amarelo e preto. 
Apesar das formas realistas, dificilmente seria confundida com uma arara real. Colocando os óculos o ponto de vista se inverte: vê-se a gaiola branca, em um ponto de vista interno, tendo, do outro lado da gaiola, a imagem do visitante, com os óculos. Também é possível enxergar os pássaros, próximos, voando ou pousados ao lado.

A construção é engenhosa do ponto de vista sensível. É possível sentir-se em um lado da sala e enxergar a partir de outro ponto, vendo o próprio corpo, a distância. Essa telepresença é o mote principal do trabalho, tendo todo o referencial dado à percepção.

Observando o estrato pragmático, a utilização de tecnologia avançada, tanto de vídeo, estereoscopia e Internet, torna o trabalho deveras interessante, tanto que vários outros trabaIhos buscam situações tecnológicas similares, com base na telepresença e telerobótica ${ }^{6}$. O esforço cognitivo é mínimo, haja vista todo o equipamento ser apresentado para proporcionar sensações visuais específicas, de modo que o equipamento ou o sistema não necessita ser pensado, mas experienciado. A tecnologia não necessita, portanto, ser decodificada, para que a obra seja compreendida em sua extensão, mas ela é base para experienciar sensivelmente o trabalho.

Já no estrato sintático-compositivo, nota-se o espaço branco em diálogo com os pássaros, em uma associação com a liberdade. O arbusto e a arara robô, em um canto da gaiola, concentram o foco de atenção do visitante, destacando-se pelas cores e posição. Os pássaros, por serem pequenos, requerem pouco a atenção quando pousados, apesar de provocar curiosidade ou estranhamento por serem expostos enquanto obra de arte, ou componentes de uma. Certamente a limpeza visual dá conta de um posicionamento distinto da gaiola, não se assemelhando a um zoológico, mas sim a um espaço expositivo: os pássaros, a gaiola, a arara robô, o arbusto, todos os elementos estão instalados meticulosamente, harmonizando-se no conjunto que adquire uma determinada organização simétrica, adquirindo equilíbrio visual.

No estrato semântico as referências são de liberdade, trazida pelos pássaros e pelo movimento de "sair de seu corpo" pro- 
porcionado pela telepresença - e pela telerobótica -, e a prisão, referida pela clausura da gaiola e pelos corpos que enclausuram o ser, este último em menor intensidade, quase nulo, pelo branco da gaiola.

Por fim, no estrato da mensagem estética, verifica-se que Rara Avis se constrói na ambigüidade de poder ver com outros olhos, livrar-se do corpo próprio e, simultaneamente, verificar a prisão que o corpo representa ao ser, ou seja, ele, o corpo, ao sustentar o ser, o prende. Ao notar a possibilidade de livrar-se do corpo próprio nota-se, também, a clausura que ele encerra. O estar fora de si, possibilitado pela tecnologia da telepresença e telerobótica, ganha uma dimensão poética de liberdade, ao mesmo tempo em que constrói uma experiência de ubiqüidade tecnológica. De modo geral, com os olhos próprios vê-se os pássaros presos; com os olhos da ave robótica, quem está preso é seu corpo, ou o dono dele, nele mesmo.

Há de se notar que a análise realizada a partir da fenomenologia da cibercepção busca efetivar um movimento que tem início na própria obra, portanto de caráter mais analítico-descritivo, alcançando uma posição interpretativa, articulando sentidos a partir da obra. Crê-se que tal movimento, da obra para seu sentido, assenta nas estruturas fenomenológicas, sistematizando o processo de análise da obras de arte tecnológica. 


\section{Notas}

1.FIGURELLI, Roberto, em texto de introdução à edição Brasileira de DUFRENNE, 1998.

2.A instalação está permanentemente conectada à Internet e permite que participantes remotos também observem o espaço da galeria a partir do ponto de vista do telerobô. Assim, o corpo do pássaro artificial é partilhado, em tempo real, por participantes locais e participantes a distância, de qualquer parte do mundo, através da Internet (T.A.).

3. "Rara Avis" (1996), uma instalação de telepresença interativa em que um pássaro robô é colocado com pássaros reais e plantas artificiais em um aviário. Usando óculos de dados ou pela Internet, visitantes não apenas controlam a cabeça cibernética do pássaro, mas também assumem sua perspectiva visual, enxergando a si próprios com as câmeras localizadas nos olhos da ave (T.A.).

4.Disponível em: <http://www.ekac.org>.

5.O termo telepresença foi empregado por Marvin Minsky no artigo Telepresença, escrito em 1980 e publicado em 1983 no livro OmniBook of Computers \& Roboters.

6. Entendido enquanto robôs não autônomos controlados a distância.

\section{Referências Bibliográficas}

ASCOTT, Roy. A arquitetura da cibercepção. In: LEÃO, Lucia (org.). Interlab: labirintos do pensamento contemporâneo. São Paulo: Iluminuras, 2002, p. 31-37.

DUFRENNE, Mikel. Estética e filosofia. $3^{\underline{a}}$ ed. Trad. Roberto Figurelli. São Paulo: Perspectiva, 1998. (Coleção Debates)

GIANNETTI, Claudia. Estética Digital - sintopía del arte, la ciencia y la tecnología. Barcelona: Associació de Cultura Contemporània L’Angelot, 2002.

HUNT, David. Eduardo Kac: Da Metáfora ao Motivo. Concinnitas, Rio de Janeiro, ano 4, n. 4, p. 77-81, março de 2003. (Dossiê Eduardo Kac)

HUSSERL, Edmund. Meditações Cartesianas - Introdução à fenomenologia. Trad. Frank de Oliveira. São Paulo: Madras, 2001.

KAC, Eduardo. Coordenação de Eduardo Kac. Apresenta vida e obra de Eduardo Kac. Disponível em: <http://www.ekac.org>. Acesso em: 12 mai 2002.

KAC, Eduardo. Genesis: a transgenic artwork. In: ASCOTT, Roy (ed.). Art, Technology, Consciousness. Portland: Intellect Books, 2000, p. 17-19.

KAC, Eduardo. Novos rumos na arte interativa. In: LEÃO, Lucia (org.). Interlab: labirintos do pensamento contemporâneo. São Paulo: Iluminuras, 2002, p.107-113. 
KAC, Eduardo. Telepresence, Biotelematics, Transgenic Art. Maribor: Kulturno izobrazevalno drustvo Kilbla = Association for Culture and Education Kibla, 2000.

KAC, Eduardo. Entrevista por Simone Osthof. In: VIS. Revista do Curso de Mestrado em Artes do Instituto de Artes da Universidade de Brasília. V.1, n. 1,p. 9-17, 1을 semestre, 1999.

MACHADO, Arlindo. El paisaje mediático: sobre el desafío de las poéticas tecnológicas. Buenos Aires: Libros del Rojas, 2000.

MERLEAU-PONTY, Maurice. Fenomenologia da Percepção. 2a ed. Trad. Carlos Alberto Ribeiro de Moura. São Paulo: Martins Fontes, 1999.

MERLEAU-PONTY, Maurice. O primado da percepção e suas conseqüências filosóficas. Trad. Constança Marcondes Cesar. Campinas, SP: Papirus, 1990.

PAREYSON, Luigi. Os problemas da estética. 3. ed. São Paulo: Martins Fontes, 1997.

RAMOS, Maria Luiza. Fenomenologia da obra literária. Rio de Janeiro: Forense, 1969.

STOCKER, Gerfried. Insurreição. Concinnitas, Rio de Janeiro, ano 4, n. 4, p. 92-94, março de 2003. (Dossiê Eduardo Kac)

WELLEK, René; WARREN, Austin. Teoria da Literatura. Lisboa: EuropaAmérica, 1962.

\section{CLEOMAR ROCHA}

Pós-doutorando do Programa de Pós-Graduação em Tecnologias da Inteligência e Design Digital (PUC-SP), Doutor em Comunicação e Cultura Contemporâneas (UFBA), Mestre em Arte e Tecnologia da Imagem (UnB), Especialista em Gestão Universitária (UNIFACS) e Licenciado em Letras (FECLIp/UEG). Membro da diretoria da ANPAP. Gerente de Projeto de Produto da Power.com. Consultor Ad Hoc da Enciclopédia de Arte e Tecnologia do Instituto Cultural Itaú. Email: cleomarrocha@gmail.com 